and Uses of Isotopically Labelled Amines", and "Enamines", of which the last at least is a considerable loss.

Among the chapters that are present, the one on "Substitution at an Amino Nitrogen" (72 pages) by Drs Challis and Butler of St Andrews really constitutes the core of the book. It is a useful collection of information laid out in a logical pattern and could well have been afforded more space at the expense of some of the other contributions. The chapter by Dr Chuchani of Caracas on "Directing and Activating Effects" is also well done and most useful. Of the first four chapters, entitled "General and Theoretical", "The Introduction of the Amine Group", "Basicity and Complex Formation", and "Detection, Determination and Characterization of Amines", the first three merit the space they take up and provide useful insight into fundamentals; the analytical chapter seeks to be comprehensive-a virtually impossible task-and thereby takes up more space (83 pages) than it probably warrants. There are also chapters on "Cleavage of the Carbon-Nitrogen Bond", "Rearrangements involving Amino Groups" (an excellent contribution), "Biological Formation and Reactions of the Amine Group", "Carbon-Nitrogen and NitrogenNitrogen Double Bond Condensation Reactions", and a rather more specialized one, "Tetraaminoethylenes".

The provision of references is extensive, though there is no specific indication of the date up to which the literature has been reviewed; this appears, in fact, to be 1965 with an extension to approximately mid-1966 in some cases. There is a useful author index to the whole volume and also a complete subject index, though the latter is not really sufficiently comprehensive. Hardly surprisingly with so many authors, the style and level of sophistication vary a good deal from one chapter to another, some offering purely a catalogue, for example, "Protection of the Amino Group", while others seek to use examples in order to develop a more reasoned theoretical approach to the particular subject under discussion. In this context one feels that rather tighter editing and perhaps a little more thought about exactly who is going to use such a volume and how they are going to use it could, in the future, produce volumes of greater value. Peter Sykes

\section{CREEP OF SOLIDS}

\section{Mechanical Behaviour of Crystalline Solids at}

\section{Elevated Temperature}

By Oleg D. Sherby and Peter M. Burke. (Progress in Materials Science, Vol. 13, No. 7.) Pp. 325-390. (Pergamon: Oxford, London and New York, 1968.) $25 s$.

IN order to justify yet another review on creep, the authors must offer something new or different from previous publications. Sherby and Burke set off on the right foot by broadening their scope to include all crystalline solids. This turns out to be somewhat pretentious, but it is not their fault because there are relatively few data on crystalline non-metals.

The first section on creep of pure metals and compounds covers temperature and stress dependence of creep. Here the authors develop in considerable detail the thesis that diffusivity and creep rate are interrelated and this is certainly a worthwhile feature. Recent work on HerringNabarro creep is emphasized with regard to its importance in ionic and covalently bonded structures and the possibility of its operation in metals. Later in this section Professor Sherby's proposal for a universal creep equation is discussed in detail. Even though this concept is not accepted by all workers in the field, the discussion should provide a stimulus to new ideas.

The section on the creep of solid solution alloys is worthwhile since the authors propose a new interpretation of available data and again provide some stimulating ideas. Finally, a short discussion is given of creep in two phase alloys where the limitations of existing knowledge are clearly pointed out.

W. J. MCG. TEgarT

\section{MATERIALS FOR ENGINEERS}

\section{Radio and Electronic Materials}

By N. P. Bogoroditskii and V. V. Pasynkov. Translated and edited by R. C. Glass. Pp. 350. (Iliffe: London, 1967.) $63 s$.

THIs book is in two parts: the first part, which deals with dielectrics, is about twice as long as the second part, which deals with conductors, semiconductors and magnetic materials. It is obvious where the weight lies, and perhaps it might not be too misleading to suggest that the book gives the appearance of being primarily one on dielectries to which other, more light weight, sections have been added. Certainly the section on semiconductors, which extends over 36 pages, seems disproportionately small in relation to the importance of its subject matter; a more extensive treatment of this section would have enhanced the value of the book.

Those who are interested in both the engineering use of materials, and in knowing why they behave the way they do, will be pleased by the manner in which this book bridges the gap between theory and practice. Books dealing with the fundamental submicroscopic physics which underlies the observed behaviour of materials tend to run to the kind of weighty quantum mechanies which makes most engineers turn elsewhere. When they do, the only alternative often seems to be the kind of handbook listing specification tests for oil-soaked press board. This book gives a theoretical treatment which, though on the whole qualitative and perhaps over-simplified in places, does at least point the direction for those who wish to make a more thorough study. On the practical side, it contains much useful information, some of it of a distinctly picturesque kind. For example: "To determine the type of silk which is being used in the insulation of a conductor it is only necessary to take the yarn and light it with a match: natural silk gives off an odour of scorched horn, and viscose gives the smell of scorched paper".

The book is a useful addition to the literature on the properties of materials used in electrical engineering, and provides a convenient survey for the engineer-physicist working in the field of materials. J. H. CALDERWOOD

\section{POLYMER SCIENCE}

\section{Advances in Polymer Science and Technology}

(Comprising papers (with discussions) read at a Joint Symposium organized by the Plasties and Polymer Group of the Society of Chemical Industry, the Institution of the Rubber Industry and the Plastics Institute, held on September 20-22, 1966. SCI Monograph No. 26.) Pp. iv +396 . (Society of Chemical Industry: London, 1967.) $100 s$.

The symposium is divided into four sessions. The first is about the structure of polymeric systems and is introduced by a review paper on crystallization and the structure of crystalline polymers. With the exception of one paper on the solvent crystallization of amorphous polyethylene terephthalate, however, the rest of the session is about the properties of amorphous polymers such as the effect of chain branching on the melt viscosity of copolymers of butadiene and divinyl benzene.

The second session is devoted primarily to the preparation and examination of the properties of polymers, including crosslinking reactions in films and adhesion to 